\title{
Molecular characterization of LMW-GS genes in Brachypodium distachyon L. reveals highly conserved Glu-3 loci in Triticum and related species
}

\author{
Shunli Wang ${ }^{1+}$, Ke Wang $^{2 \dagger}$, Guanxing Chen ${ }^{1+}$, Dongwen Lv ${ }^{1 \dagger}$, Xiaofeng Han ${ }^{1}$, Zitong Yu' ${ }^{1}$ Xiaohui Li ${ }^{1}$, \\ Xingguo Ye ${ }^{2^{*}}$, SLK Hsam ${ }^{3}$, Wujun Ma ${ }^{4^{*}}$, Rudi Appels ${ }^{4}$ and Yueming Yan ${ }^{1^{*}}$
}

\begin{abstract}
Background: Brachypodium distachyon L. is a newly emerging model plant system for temperate cereal crop species. However, its grain protein compositions are still not clear. In the current study, we carried out a detailed proteomics and molecular genetics study on grain glutenin proteins in B. distachyon.

Results: SDS-PAGE and RP-HPLC analysis of grain proteins showed that Brachypodium has few gliadins and high molecular weight glutenin subunits. In contrast the electrophoretic patterns for the albumin, globulin and low molecular weight glutenin subunit (LMW-GS) fractions of the grain protein were similar to those in wheat. In particular, the LMW-C type subunits in Brachypodium were more abundant than the equivalent proteins in common wheat. Southern blotting analysis confirmed that Brachypodium has 4-5 copies of LMW-GS genes. A total of 18 LMW-GS genes were cloned from Brachypodium by allele specific PCR. LMW-GS and 4 deduced amino acid sequences were further confirmed by using Western-blotting and MALDI-TOF-MS. Phylogenetic analysis indicated that Brachypodium was closer to Ae. markgrafii and Ae. umbellulata than to T. aestivum.

Conclusions: Brachypodium possessed a highly conserved Glu-3 locus that is closely related to Triticum and related species. The presence of LMW-GS in B. distachyon grains indicates that B. distachyon may be used as a model system for studying wheat quality attributes.
\end{abstract}

\section{Background}

Cereals are the main cultivated crops in agriculture, including rice (Oryza sativa L.), wheat (Triticum aestivum L.), barley (Hordeum vulgare L.), rye (Secale cereale L.), oats (Avena sativa L.), maize (Zea mays L.) and sorghum (Sorghum bicolor L.). They belong to the family of the Poaceae. The major grain proteins in cereal crops are storage proteins, accounting for about $60-80 \%$ of total proteins depending on species and varieties. Prolamins are major seed storage proteins in wheat, barley, rye and

\footnotetext{
* Correspondence: yexg@mail.caas.net.cn; w.ma@murdoch.edu.au; yanym@ hotmail.com

${ }^{\dagger}$ Equal contributors

${ }^{2}$ Institute of Crop Sciences, Chinese Academy of Agricultural Sciences/ National Key Facility for Crop Gene Resources and Genetic Improvement, 100081 Beijing, China

Full list of author information is available at the end of the article
}

maize, and are important nutrition and food sources for both humans and animals. Globulins are the predominant storage proteins in oat and rice, accounting for about $70-80 \%$ of the total seed proteins [1]. Previous studies have been largely focused on wheat, rice, maize and sorghum due to their importance as food crops in the world. In wheat the major seed storage proteins include glutenins and gliadins that are the primary determinations of dough elasticity and extensibility, respectively [2], and both protein groups play a key role in the processing of wheat flour into different baked products.

So far, many prolamin genes have been cloned, not only in common wheat but also in its related species such as Aegilops L., Agropyron cristatum, Thinopyrum intermedium, Lophopyrum elongatum, Dasypyrum villosum, Crithopsis delileana, Eremopyrum distans, and Taeniatherum caput-medusae [3-10]. The major protein 
components in milled rice or rice endosperm were glutenins, which are different from the prolamins in other cereals [11]. Rice (Oryza sativa L.) as a major crop with a relatively small genome (about $451 \mathrm{Mbp}$ ) has been promoted as a model system of monocots [12]. However, its relatively longer life cycle, large physical stature and special semiaquatic growth requirement limited its wide usage as a model system. Brachypodium distachyon L. (B. distachyon), a member of the Pooideae subfamily and a temperate wild annual grass endemic to the Mediterranean and Middle East [13], has been rapidly established as a model plant system especially as an experimental model organism for grasses and cereals. It possesses many attractive attributes such as small genome (diploid with about $355 \mathrm{Mbp}$ ), short growth cycle, self-fertility and simple growth requirements $[13,14]$, as well as competence to be efficiently transformed [15-17]. Furthermore the B. distachyon genome exhibits a high level of colinearity and synteny to the genomes of temperate cereal crops [18]. Thus, it has facilitated a range of studies in comparative genomics of cereals, including wheat, rice, and even Aegliops species.

Phylogenic analysis has classified B. distachyon to be closer to wheat and barley than to rice, corn or sorghum $[19,20]$. An efficient transformation procedure and an optimized plant regeneration protocol have been developed for B. distachyon, including conditions for inducing embryogenic callus [21] and biolistic transformation $[15,16]$. Vogel and Hill [22] identified an inbred diploid line, Bd21-3, with high transformation efficiencies. Despite these substantial studies and accumulated knowledge, its grain proteins and compositions are still not clear. Laudencia-Chingcuanco and Vensel [23] demonstrated that globulins are the main seed storage proteins in $B$. distachyon based on sodium dodecyl sulphate polyacrylamide gel electrophoresis (SDS-PAGE) and mass spectrometry (MS) analyses in a diploid accession Bd21. Larré et al. [24] found that globulins and a few prolamins in Bd21-3, a diploid inbred line originated from Bd21. Wang et al. [25] identified 18 storage proteins and 15 albumin proteins in Bd21, including a high molecular weight glutenin subunit (HMW-GS). However, so far low molecular weight glutenin subunits (LMW-GS) and their gene organizations in $B$. distachyon remain unknown although the genome sequencing of $B$. distachyon is completed.

In this work, LMW-GS in B. distachyon were separated and characterized by a proteomic approach and their encoding genes were isolated by allele specific PCR (AS-PCR). A phylogenetic analysis among cereal crops was also carried out. Our results revealed that a highly conserved Glu-3 locus is present in B. distachyon being similar to that in Triticum and Aegilops species.

\section{Results}

Separation and characterization of $B$. distachyon grain proteins

The grain protein compositions of 6 accessions of $B$. distachyon (Bd4, $\mathrm{Bd} 10, \mathrm{Bd} 11, \mathrm{Bd} 13, \mathrm{Bd} 16$ and $\mathrm{Bd} 21)$ and 2 common wheat cultivars (Chinese Spring and Kontrast) were analysed. The protein fractions analyzed included albumins, globulins, gliadins and glutenins. The results showed that the SDS electrophoresis patterns of albumins and globulins in B. distachyon accessions as well as their overall amount were generally similar to those of common wheat although there were differences in certain protein subunits and expression levels (Figure 1a-c). In contrast, the gliadins, HMW-GS and LMW-GS compositions displayed clear differences between $B$. distachyon and wheat. Only a few gliadin bands in $B$. distachyon were present in the lower molecular weight area on SDS-PAGE gels as shown in Figure 1d. Based on Figure 1e, the B. distachyon accessions had B and $C$ but very few $A$ and $D$ type subunits, suggesting that $B$. distachyon accessions possess few HMW glutenin subunits. This result was similar to the previous report [25]. Meanwhile, B. distachyon accessions had similar LMW glutenin compositions to these of common wheat. The LMW C-type subunits were much more prominent than those of common wheat in both subunit components and expression levels. At least 9 distinct bands of each accession were visualized after staining on the SDS-PAGE gel.

In order to confirm our results, LMW-GS in B. distachyon were extracted with a wheat glutenin extraction method and separated by SDS-PAGE, and then transferred to PVDF membrane for Western-blotting and antibody-based identification. As shown in Figure 2, some positive signals could be observed for the LMW-B bands of both CS and B. distachyon, indicating the presence of LMW-GS in B. distachyon. Further Southern blotting analysis, using wheat LMW-GS gene as probe, demonstrated that the copies of LMW-GS genes in diploid Brachypodium distachyon 21 were 4-5 (Figure 2c).

The results of RP-HPLC analysis from Bd21, Bd13 and Bd16 as well as Chinese Spring are shown in Figure 3. It is known that proteins are separated by RP-HPLC according to their surface hydrophobicities and proteins with higher hydrophobicities elute faster than those with lower hydrophobicities. HMW-GS have been shown to have higher surface hydrophobicities and therefore elute earlier than LMW-GS [26]. As shown in Figure 3, HMW-GS and LMW-GS of Chinese Spring eluted at 15-30 $\mathrm{min}$ and 30-45 min, respectively. Interestingly, the LMW-GS from $B$. distachyon had similar elution time of HMW-GS from Chinese Spring, suggesting that they have similar hydrophobicities. Thus, although Brachypodium and common wheat had similar LMW-GS 


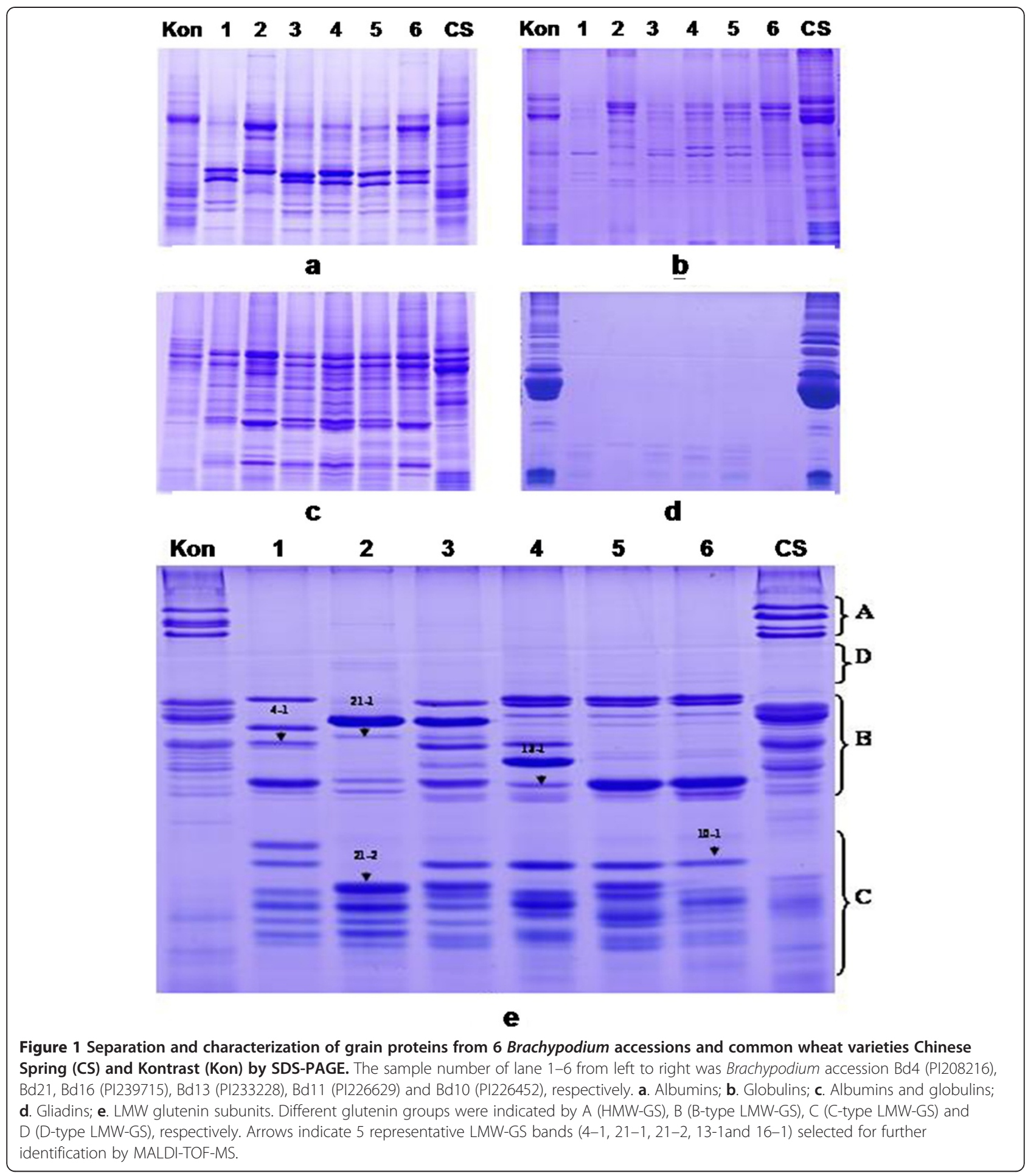

electrophoretic compositions, their protein structures and properties might be different.

\section{Molecular characterization of LMW-GS genes from}

\section{B. distachyon}

According to SDS-PAGE, Western blotting, Southern blotting and RP-HPLC analysis, Brachypodium has a homologous Glu-3 locus that is similar to that in common wheat. Different AS-PCR primers for wheat LMW-GS genes were used to amplify the homologous genes from $B$. distachyon. In the current study, a total of 18 LMW-GS genes were amplified, cloned and sequenced from $B$. distachyon, including $12 \mathrm{LMW}-\mathrm{m}$ and $6 \mathrm{LMW}-\mathrm{i}$ type genes. The PCR amplification products on the agarose gel were 


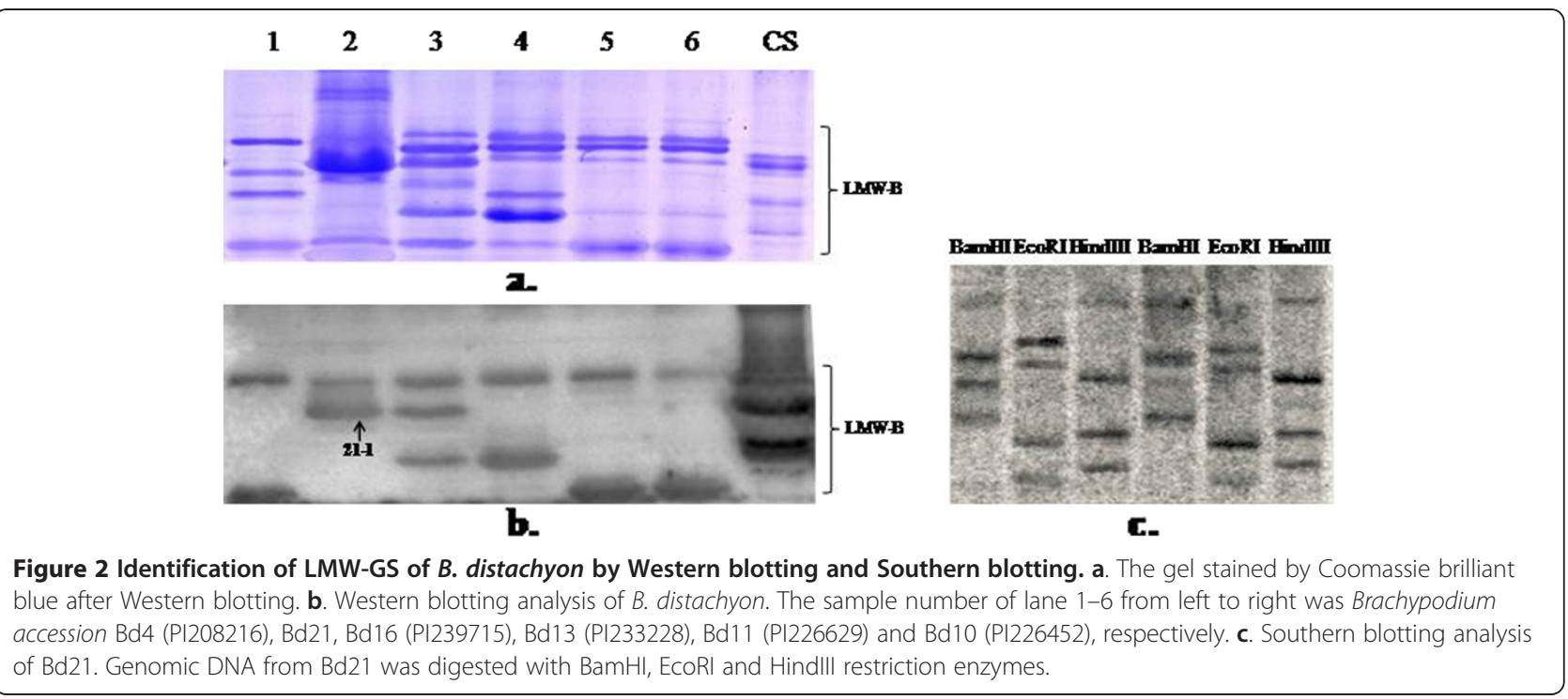

showed in Additional file 1. All genes were deposited in GenBank (accession numbers in Table 1). Of the 18 genes cloned, 12 LMW-m type genes were from hexaploid Brachypodium while $6 \mathrm{LMW}-\mathrm{i}$ type genes were from diploid and hexaploid Brachypodium (HQ220189 and HQ220190 from Bd4, HQ220195 and HQ220197 from Bd10, HQ220191 and HQ220193 from Bd21).

Comparative analysis of the nucleotide and the deduced protein sequences showed that all LMW-GS genes isolated from $B$. distachyon had the typical structural characteristics with those of common wheat and related species (Figure 4). The deduced protein sequences had a common structure model: a conserved 20 residues signal peptide, a 13 residues $\mathrm{N}$-terminal domain (deletion in LMW-i type), a variable repetitive domain, and three subregions of the C-terminal domain. It is evident that Brachypodium had highly homologous Glu-3 loci to those in Triticum and related species.

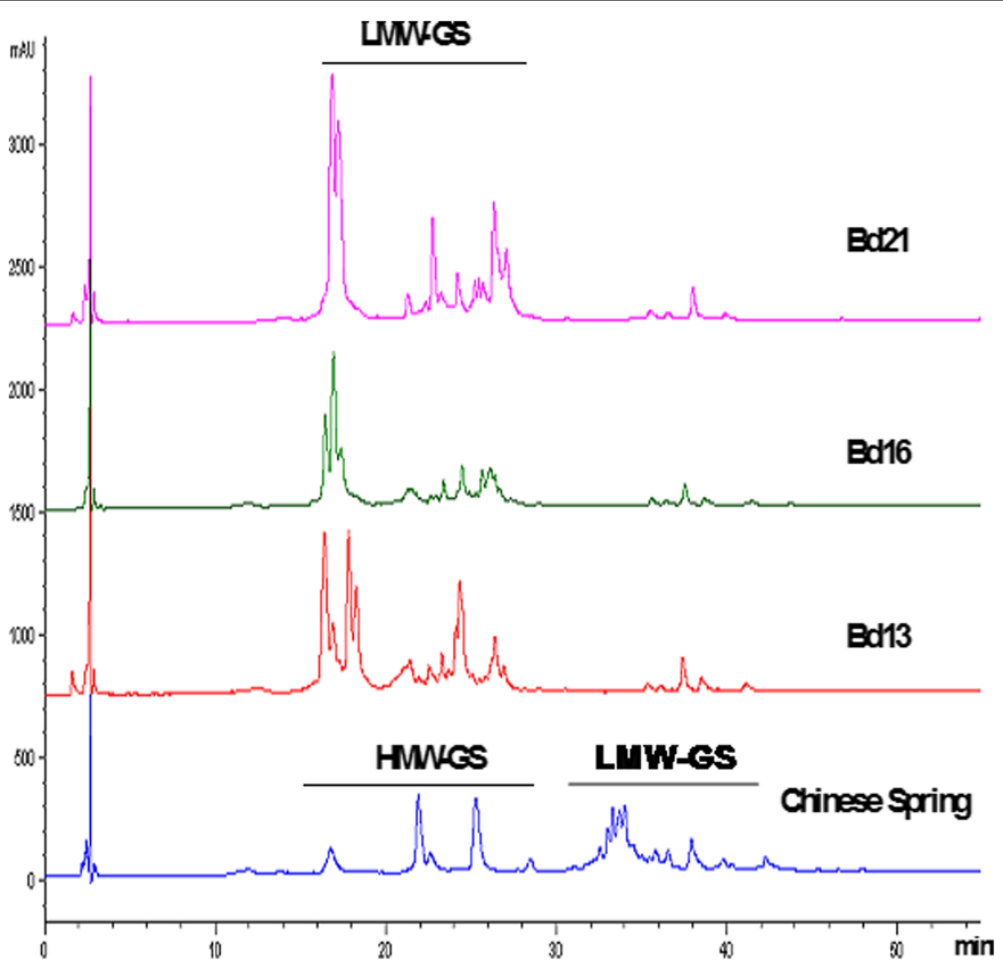

Figure 3 Separation of glutenin subunits from Bd21, Bd16, Bd13 and Chinese Spring by RP-HPLC. HMW-GS and LMW-GS were indicated. 
Table 1 The cloned LMW-GS genes from B. distachyon $\mathrm{L}$

\begin{tabular}{|c|c|c|c|c|c|}
\hline B. distachyon accessions & GenBank accession No. & Size (bp) & Deduced amino acid $M r$ & Type & No. of Cysteine \\
\hline \multirow[t]{2}{*}{ Bd4 (PI208216, 6n=30) } & HQ220189 & 1170 & $42.678 \mathrm{KD}$ & LMW-i & 8 \\
\hline & HQ220190 & 1095 & $39.839 \mathrm{KD}$ & LMW-i & 8 \\
\hline \multirow[t]{5}{*}{ Bd10 (PI226452, 6n=30) } & HQ220192 & 897 & $31.748 \mathrm{KD}$ & LMW-m & 8 \\
\hline & HQ220194 & 894 & $31.437 \mathrm{KD}$ & LMW-m & 8 \\
\hline & HQ220196 & 885 & $31.223 \mathrm{KD}$ & LMW-m & 8 \\
\hline & HQ220195 & 1038 & $37.723 \mathrm{KD}$ & LMW-i & 8 \\
\hline & HQ220197 & 1035 & $37.568 \mathrm{KD}$ & LMW-i & 8 \\
\hline \multirow[t]{5}{*}{ Bd11(PI226629, 6n=30) } & HQ220199 & 885 & $31.257 \mathrm{KD}$ & LMW-m & 8 \\
\hline & HQ220201 & 885 & $31.279 \mathrm{KD}$ & LMW-m & 8 \\
\hline & HQ220202 & 900 & $31.794 \mathrm{KD}$ & LMW-m & 9 \\
\hline & HQ220203 & 885 & $31.333 \mathrm{KD}$ & LMW-m & 8 \\
\hline & HQ220204 & 900 & $31.728 \mathrm{KD}$ & LMW-m & 9 \\
\hline \multirow[t]{2}{*}{ Bd13(PI 233228, 6n=30) } & HQ220205 & 894 & $31.410 K D$ & LMW-m & 8 \\
\hline & HQ220206 & 885 & $31.229 K D$ & LMW-m & 7 \\
\hline \multirow[t]{2}{*}{ Bd16(PI 239715, 6n=30) } & HQ220198 & 894 & $31.377 \mathrm{KD}$ & LMW-m & 8 \\
\hline & HQ220200 & 894 & $31.437 \mathrm{KD}$ & LMW-m & 8 \\
\hline \multirow[t]{2}{*}{$\mathrm{Bd} 21(\mathrm{PI} 254867,2 \mathrm{n}=10)$} & HQ220191 & 1164 & $42.551 \mathrm{KD}$ & LMW-i & 8 \\
\hline & HQ220193 & 1134 & $41.360 \mathrm{KD}$ & LMW-i & 8 \\
\hline T. aestivum cv. Chinese Spring & FJ615311 & 924 & $32.863 \mathrm{KD}$ & LMW-m & 8 \\
\hline T. aestivum cv. Chinese Spring & AY453154 & 1131 & $41.266 \mathrm{KD}$ & LMW-i & 8 \\
\hline
\end{tabular}

Sequence comparative analysis of $12 \mathrm{LMW}-\mathrm{m}$ and 6 LMW-i type genes showed a higher similarity. Thus, 5 typical LMW-m and LMW-i type genes were used to identify SNPs and InDels through comparison with 23 wheat LMW-GS genes from GenBank, and the results were showed in Table 2 and Table 3. For the 5 LMW-m type genes, a total of 34 SNPs were identified at different positions, and the numbers of SNPs in HQ220202, HQ220206, HQ220198, HQ220194, and HQ220200 were $4,9,8,7$ and 6, respectively. A total of 31 SNPs, accounting for $91.17 \%$, were resulted from $A \rightarrow G$ or $\mathrm{C} \rightarrow \mathrm{T}$ transition, slightly higher than that of LMW-i type genes from Triticum momoccocum [27]. The remaining 3 SNPs $(8.83 \%)$ were generated from $\mathrm{T} \rightarrow \mathrm{A}$ or $\mathrm{C} \rightarrow \mathrm{A}$ transition. Of the 34 SNPs detected, 22 variations belonged to nonsynonymous and 12 were synonymous mutations. No InDels were found among the $5 \mathrm{LMW}-\mathrm{m}$ type genes. For the $5 \mathrm{LMW}$-i type genes, only 9 SNPs were detected (Table 3), of which 7 were nonsynonymous substitutions. Both HQ220195 and HQ220191 had a synonymous substitution. In particular, HQ220190 had no SNPs, but contained 6 deletions at the position 346 (C), 349-350 (CA), 352-353 (CA), 355 (C), 391 (T), 397-404 (CAACAACA). All nucleotide acid deletions encoded a glutamine residue, except for the position 391 that encoded a serine.

Both HQ220202 and HQ220204 had an extra cysteine located at the $4^{\text {th }}$ residue in the C-terminal III domain, resulting from $\mathrm{T} \rightarrow \mathrm{G}$ dot mutation and leading to the cysteine generation from glycin. Additionally, HQ220206 only had 7 cysteine, and one cysteine residue was deleted in the C-terminal II domains, which was resulted from a $\mathrm{G} \rightarrow \mathrm{A}$ transition, and led to generate a tyrosine (TAT) from cysteine (TGT).

\section{LMW-GS determination by mass spectrometry}

Mass spectrometry has shown to be effective in gaining structural information of glutenins and globulins directly isolated from seeds $[23,28-30]$. According to the deduced molecular masses $(31-42 \mathrm{kDa})$ of LMW-GS genes isolated from Brachypodium in this work, 5 representative protein bands on the SDS-PAGE (Figure 1e), corresponding to different molecular mass ranges, were chosen to further identify by MALDI-TOF-MS after trypsin digestion. The standard error $(\mathrm{M}+\mathrm{H})^{+}$was based on Sun et al. [28] which was set to less than 3.212. The results of the mass spectrometric identifications were summarized in Table 4.

The calculated mass spectra of trypsin digested 18 deduced LMW-GS were compared with 5 MALDITOF measured peptide mass spectra, four LMW-GS HQ220190, HQ220191, HQ220195 and HQ220198 were well matched with subunits 4-1, 21-1, 13-1 and 10-1, respectively (Table 4, Additional file 2, Additional file 3, Additional file 4 and Additional file 5), indicating that they are true native subunits in Brachypodium grains. 


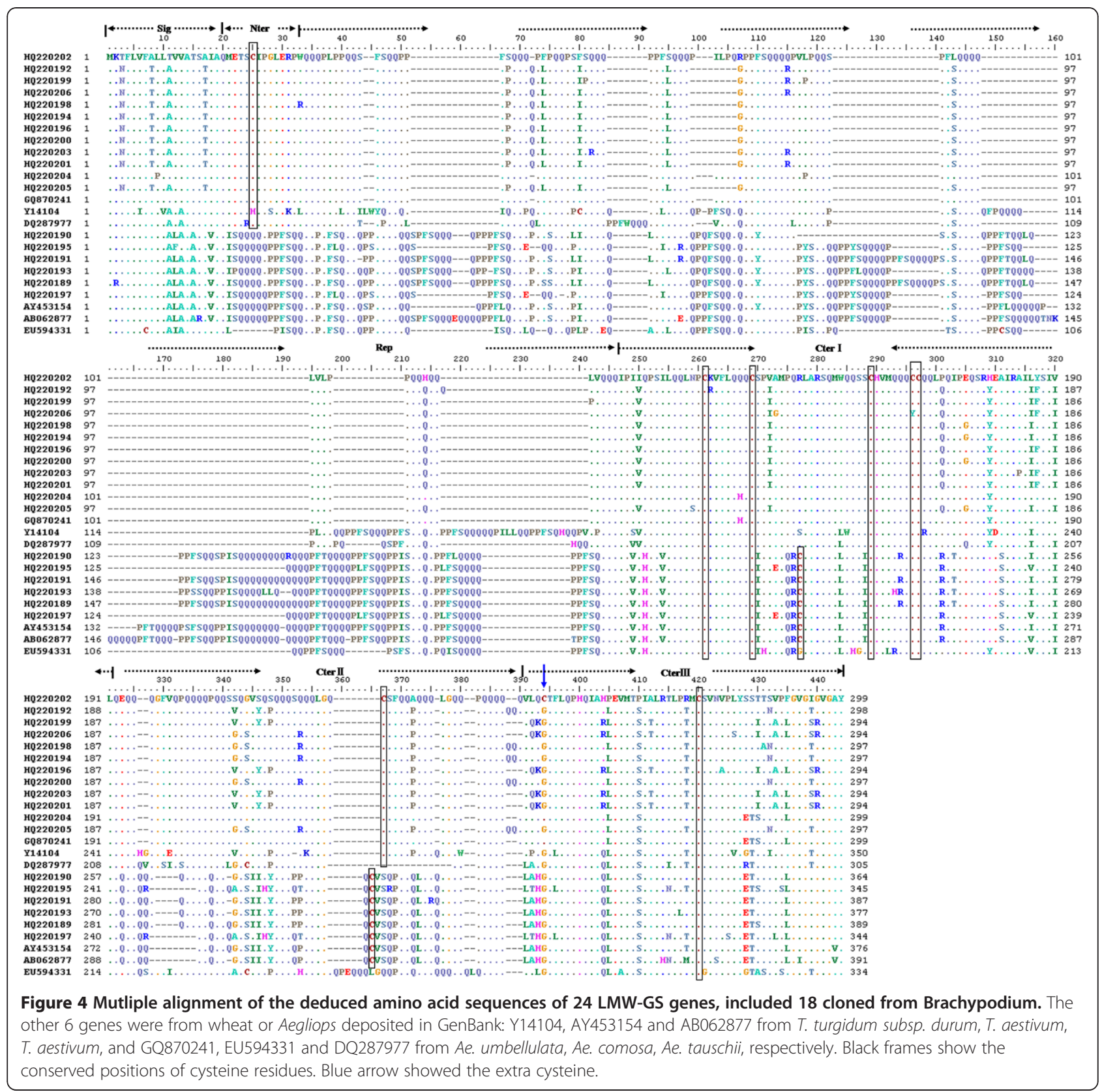

Table 2 The positions of SNPs and InDels identified among 5 LMW-m type genes

\begin{tabular}{|c|c|c|c|c|c|c|c|c|c|c|c|c|c|c|c|c|c|c|c|c|c|}
\hline LMW-GS & 22 & 97 & 108 & 582 & 669 & 722 & 749 & 760 & 780 & 785 & 801 & 843 & 905 & 1033 & 1055 & 1058 & 1072 & 1078 & 1121 & 1135 & 1142 \\
\hline HQ220202 & G & $\mathrm{T}$ & A & C & $\mathrm{T}$ & G & A & C & C & A & A & A & A & $\mathrm{T}$ & A & C & C & $\mathrm{G}$ & $\mathrm{T}$ & A & $\mathrm{T}$ \\
\hline HQ220206 & A & $\mathrm{T}$ & A & $\mathrm{T}$ & $\mathrm{T}$ & A & A & $\mathrm{T}$ & C & $\mathrm{T}$ & G & A & G & $\mathrm{T}$ & G & $\mathrm{T}$ & $\mathrm{T}$ & A & C & A & C \\
\hline HQ220198 & A & A & A & $\mathrm{T}$ & $\mathrm{T}$ & G & G & $\mathrm{T}$ & $\mathrm{T}$ & A & G & A & G & C & A & $\mathrm{T}$ & $\mathrm{T}$ & G & $\mathrm{T}$ & G & $\mathrm{T}$ \\
\hline HQ220194 & A & $\mathrm{T}$ & G & $\mathrm{T}$ & A & G & G & $T$ & $\mathrm{~T}$ & A & G & A & G & $\mathrm{T}$ & A & $T$ & $T$ & G & $T$ & A & $\mathrm{T}$ \\
\hline HQ220200 & A & $\mathrm{T}$ & A & $\mathrm{T}$ & $\mathrm{T}$ & G & G & $\mathrm{T}$ & $\mathrm{T}$ & A & G & G & G & $\mathrm{T}$ & A & $\mathrm{T}$ & $\mathrm{T}$ & G & $\mathrm{T}$ & A & $\mathrm{T}$ \\
\hline 23 otherLMW-m Genes* & G & $\mathrm{T}$ & A & $\mathrm{T}$ & $\mathrm{T}$ & G & A & $\mathrm{T}$ & C & A & A & A & A & $\mathrm{T}$ & A & $\mathrm{T}$ & $\mathrm{T}$ & G & $\mathrm{T}$ & A & $\mathrm{T}$ \\
\hline
\end{tabular}

*Other 23 LMW-m genes were from GenBank, including EU329425 (Ae. markgrafii), EU594338 (Ae. comosa), EU571721 and FJ824795 (Ae. speltoides), DQ287977 (Ae. tauschii), GQ870236 (Ae. triuncialis), FJ824801 (Ae. bicornis), EU571719 (Ae. columnaris), GQ389630 and GQ389629 (Ae. cylindrica), EF188286 (Ae. geniculata), GQ389632, EU305555 and EU189089 (Ae. longissima), GQ870241 and EU571725 (Ae. umbellulata), FJ824799 (Ae. searsii), AB062852 (T. aestivum), Y14104 and EF188290 (T. turgidum subsp.durum), AY263369, AB062868 and FJ615311 (T. aestivum). 
Table 3 The positions of SNPs and InDels identified among 5 LMW-i type genes*

\begin{tabular}{|c|c|c|c|c|c|c|c|c|c|c|c|c|c|c|}
\hline LMW-GS & 38 & 251 & 275 & 346 & $349-350$ & $352-353$ & 355 & 391 & $397-404$ & 464 & 789 & 1116 & 1040 & 1117 \\
\hline HQ220190 & $C$ & A & A & - & - & - & - & - & -————- & $\bar{T}$ & $G$ & $A$ & A & $T$ \\
\hline HQ220195 & $T$ & G & $A$ & C & CA & CA & C & $T$ & CAACAACA & $T$ & G & G & A & C \\
\hline HQ220191 & C & A & G & C & CA & $C A$ & C & $\mathrm{T}$ & CAACAACA & $T$ & G & $A$ & G & $T$ \\
\hline HQ220193 & C & A & $A$ & C & $C A$ & $C A$ & C & $T$ & CAACAACA & C & C & $A$ & A & $T$ \\
\hline HQ220197 & C & A & $A$ & C & CA & CA & C & T & CAACAACA & T & G & $A$ & $A$ & C \\
\hline \multicolumn{15}{|l|}{23 other } \\
\hline LMW-m Genes & C & A & A & C & $C A$ & CA & C & $T$ & CAACAACA & $T$ & G & A & $A$ & $T$ \\
\hline
\end{tabular}

*Horizontal dashes indicated the deletions of nucleotide. Other 23 LMW-i genes from GenBank included GQ870245 (Ae. markgrafii), GQ870242 (Ae. umbellulata), GQ870246 (Ae. speltoides), EU594331, EU594335 and EU594336 (Ae. comosa), EF536030 (Ae. juvenalis), EF536035 (Ae. geniculata), AY606257 and AY724436 (L. elongatum), GQ870247 (T. urartu), DQ217661 and DQ217663 (T. turgidum subsp. dicoccoides), DQ345449 (T. monococcum L.), AY453154, AY453155, AY453157, AY453160, EU189087, FJ549932, FJ755303, FJ755304 and AB062877 (T. aestivum).

The subunit 21-1 has been detected by the Western blotting (Figure 2), and thus the mass spectra results further confirmed that this band was LMW-GS. The remaining Band 21-2 was identified as prolamine (Additional file 6 and Additional file 7), which is likely to be a C-type LMW-GS, corresponding to $\alpha / \beta$ - and $\gamma$-gliadins modified in the number of cysteine residues [31].
Phylogenetic evolutionary analysis among B. distachyon, Triticum and Aegliops species

A total of 39 storage protein genes were used to construct phylogenetic trees and to investigate their evolutionary relationships among Brachypodium, Aegliops, and Triticum species as well as other cereal crops with complete nucleotide coding sequences. These storage protein genes

Table 4 Protein identification from SDS-PAGE bands in B. distachyon by MALDI-TOF-MS

\begin{tabular}{|c|c|c|c|c|c|c|}
\hline $\begin{array}{l}\text { LMW-GS } \\
\text { Genes }\end{array}$ & $\begin{array}{l}\text { LMW-GS } \\
\text { subunit }\end{array}$ & $\begin{array}{l}\text { Measured mass } \\
(\mathrm{M}+\mathrm{H})+\end{array}$ & $\begin{array}{l}\text { Calculated mass } \\
(\mathrm{M}+\mathrm{H})+\end{array}$ & $\begin{array}{l}\text { Missed } \\
\text { cleavage }\end{array}$ & $\begin{array}{l}\text { Peptide sequences predicted } \\
\text { by PeptideMass }\end{array}$ & Positions \\
\hline \multirow[t]{6}{*}{ HQ220190 } & $4-1$ & 845.4112 & 842.4913 & 0 & QTPEQSR & $218-224$ \\
\hline & & 1088.5128 & 1091.5411 & 0 & QCCQQLR & $211-217$ \\
\hline & & 1704.7904 & 1707.8036 & 1 & QCCQQLRQTPEQSR & $211-224$ \\
\hline & & 1765.9240 & 1765.7693 & 0 & VFLQQQCIPVAMQR & 179-192 \\
\hline & & 1793.8608 & 1794.8394 & 0 & SQMLQQSICHVMQR & $197-210$ \\
\hline & & 2120.0925 & 2119.0759 & 1 & VFLQQQCIPVAMQRCLAR & 179-196 \\
\hline \multirow[t]{8}{*}{ HQ220191 } & $21-1$ & 845.4112 & 842.5071 & 0 & QTPEQSR & $241-247$ \\
\hline & & 878.3971 & 879.4393 & 0 & QCCQQLR & $234-240$ \\
\hline & & 1704.7904 & 1707.8132 & 1 & QCCQQLRQTPEQSR & $234-247$ \\
\hline & & 1765.9240 & 1765.7466 & 0 & VFLQQQCIPVAMQR & $202-215$ \\
\hline & & 1793.8608 & 1791.7360 & 0 & SQMLQQSICHVMQR & $220-233$ \\
\hline & & 2104.0976 & 2102.0032 & 1 & VFLQQQCIPVAMQRCLAR & 202-219 \\
\hline & & 2342.1501 & 2342.9780 & 1 & CLARSQMLQQSICHVMQR & $216-233$ \\
\hline & & 2643.3044 & 2643.3130 & 0 & MCSVNVPLYETTTSVPLGVG IGVGAY & $342-367$ \\
\hline \multirow[t]{6}{*}{ HQ220195 } & $13-1$ & 1479.7662 & 1482.8090 & 1 & QIPEQSRHESIR & $202-213$ \\
\hline & & 1687.9490 & 1687.8210 & 0 & AIVYSIILQQQQQR & $214-227$ \\
\hline & & 1718.8716 & 1723.8390 & 0 & VFLQQQCIPVEMQR & 163-176 \\
\hline & & 1734.8665 & 1735.8500 & 0 & VFLQQQCIPVEMQR & 163-176 \\
\hline & & 1823.9295 & 1828.8950 & 0 & VFLQQQCIPVEMQR & 163-176 \\
\hline & & 2162.1031 & 2161.0060 & 1 & VFLQQQCIPVEMQRCLAR & 163-180 \\
\hline \multirow[t]{6}{*}{ HQ220198 } & $10-1$ & 1593.7876 & 1595.7630 & 0 & METSCIPGLERPR & $1-13$ \\
\hline & & 1850.9404 & 1851.8900 & 0 & VFLQQQCSPIAMPQR & $109-123$ \\
\hline & & 2086.1048 & 2085.9630 & 1 & VFLQQQCSPIAMPQRLAR & 109-126 \\
\hline & & 2102.0997 & 2102.0290 & 1 & VFLQQQCSPIAMPQRLAR & 109-126 \\
\hline & & 3337.4388 & 3337.6920 & 0 & SQMWQQSSCHVMQQQCCQQLQQIPGQSR & $127-154$ \\
\hline & & 3960.8448 & 3963.8230 & 1 & LARSQMWQQSSCHVMQQQCCQQLQQIPGQSR & $124-154$ \\
\hline
\end{tabular}


included 18 LMW-GS genes from $B$. distachyon in this work, 8 and 11 LMW-GS genes from Triticum and related genomes (A, B, D, C, N, U, M, $S^{\mathrm{s}}, \mathrm{S}^{\mathrm{b}}$ ) from the GenBank, respectively, and a B-hordein from barley and a secalin gene from rye (Figure 5). The results showed that 12 LMW-m and 6 LMW-i genes were tightly clustered into one branch. The omega-secalin gene from rye was obviously clustered into a separated group. The Bhordein gene from barley was clustered in a branch with the LMW-GS genes, but showing a significant difference in sequence homology. Among the LMW-GS gene subgroup, 2 clades corresponding to the LMW-m \& $\mathrm{s}$ and LMW-i type genes were separated. The LMW-m genes from $B$. distachyon were clustered with Ae. markgrafii and Ae. umbelluta in the first clade while the LMW-i genes from Brachypodium were clustered with the A genome genes from Triticum aestivum and $\mathrm{C}$ genome of Ae. markgrafii. These results suggested that the LMW glutenin genes from Brachypodium were closer to Aegilops than to Triticum at the Glu-3 loci.

\section{Discussion}

LMW-GS as important grain storage proteins in

\section{B. distachyon}

Based on the solubility in a series of solvents, plant proteins are traditionally classified into water-soluble proteins

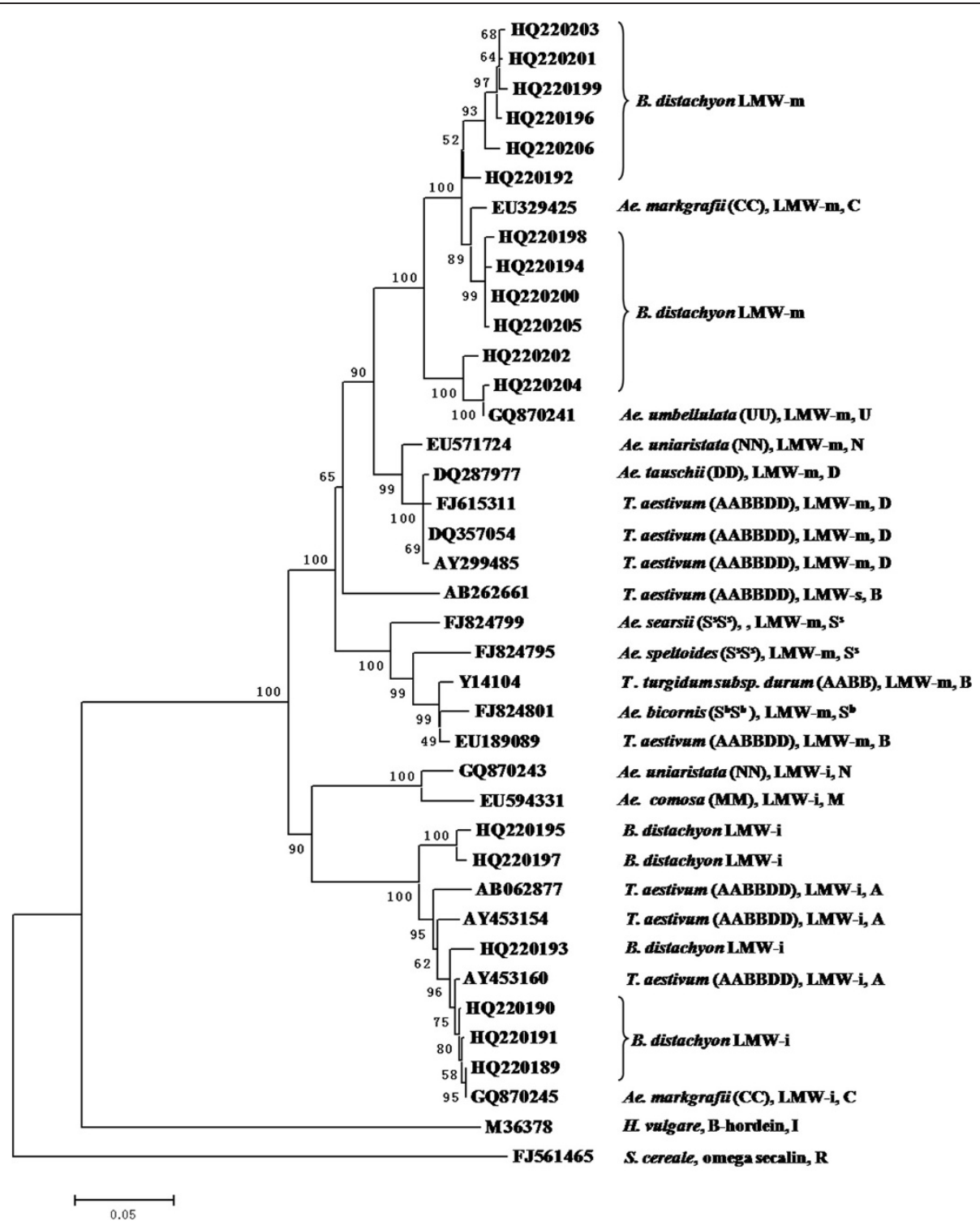

Figure 5 the phylogenetic tree showed the relationships among Brachypodium, Aegilops and Triticum species based on the LMW-GS genes. All LMW-GS genes cloned from Brachypodium were used to construct phylogenetic tree. Nucleotide sequences are specified by their accession number. A, B, or D at the end of the accession number indicates the chromosomal assignment of their sequences. 
(albumins), saline-soluble proteins (globulins) and alcoholsoluble proteins (prolamins) [1]. Different plant species generally have one predominant protein type in the grain endosperm. Laudencia-Chingcuanco and Vensel [23] reported that globulins were the main seed storage proteins in $B$. distachyon. But in their work, only 7 major protein bands were detected by SDS-PAGE and mass spectrometry, of which 6 were identified as globulins. Glutenins and gliadins were not extracted and analyzed. Recently, LMWGS like proteins were identified by SDS-PAGE, and their masses were determined by MALDI-TOF in B. distachyon [25]. These suggest that Brachypodium grains may contain LMW-GS like proteins.

Our results demonstrated that Brachypodium grains had similar electrophoretic compositions with common wheat in LMW glutenin subunits, In particular, B. distachyon appeared to have more abundant LMW-C type subunits than wheat (Figure 1). A total of 18 LMW-GS genes isolated from $B$. distachyon displayed highly homologous with those from Triticum and Aegilops species. The presence of LMW-GS in B. distachyon was further confirmed by Western blotting, Southern blotting and MALDI-TOF-MS (Table 4, Figure 2 and Additional file 2, Additional file 3, Additional file 4, Additional file 5, Additional file 6 and Additional file 7). Glutenins play important roles in the plant life cycle [1]. Therefore, the primary role of LMW-GS in B. distachyon is probably involved in providing energy and nutrition for seed germination.

\section{Allelic variations and gene organization at Glu-3 in B. distachyon}

High homology of LMW-GS genes between Brachypodium and common wheat and related species was found in this work (Figure 4-5), including similar gene sizes and structural characteristics. This suggests that a highly conserved Glu-3 locus is present in B. distachyon. Of the 18 LMWGS genes isolated from $B$. distachyon, extensive allelic variations were detected, including 34 and 9 SNPs in 5 typical LMW-m and LMW-i type genes, respectively, and 6 deletions present in the LMW-i type gene HQ220190. Particularly, both HQ220202 and HQ220204 had an extra cysteine, locating at the same position as GQ870250 and GQ870241 from Ae. markgrafii and Ae. umbellulata, respectively [32] (Figure 4). Thus, they probably represent an ancient type among the LMW-GS gene family. On the other hand, as in previous reports [9], HQ220206 only had 7 cysteine residues and a cysteine in the C-terminal II domain was changed into tyrosine because of a $\mathrm{G} \rightarrow \mathrm{A}$ transition. Therefore, the abundant SNP and InDel variations present in the LMW-GS genes of $B$. distachyon could result in different biochemical properties of their deduced protein subunits such as higher surface hydrophobicity as revealed by RP-HPLC (Figure 3).

The LMW-m and LMW-i genes isolated from $B$. distachyon were used to blast at the Brachypodium genome project websites (www.phytozome.net and http://www. brachypodium.org/). The blast results only returned one locus, Bradi3g17070, which had some sequence similarity with the LMW-GS genes cloned in this work. However, Bradi3g17070 was more similar to gliadin or avenin-like seed proteins. This suggests that the data of the Glu-3 locus encoding for LMW-GS in B. distachyon is not present in the genome sequence database.

So far, although considerable work was carried out, the precise gene organizations at the Glu-3 loci in wheat and related species are still unclear. LMW-GS can be devided to LMW-s, LMW-m, and LMW-i types according to the first amino acid residue of the mature protein, serine, methionine, or isoleucine, respectively [33]. LMWGS are encoded by multiple gene family at the Glu-3 loci of A, B, D chromosomes of common wheat [33]. Some other related genomes, e.g. S, C, M, N and U also contain highly homologous Glu-3 loci $[8,9,32]$. According to previous reports, the copy numbers of the LMW-GS genes in common wheat were estimated to be 10-15 [33,34] or 35-40 [35-37]. Wicker et al. [38] found that two LMW-i type genes from the A genome of Triticum monococcum that were located more than $150 \mathrm{kbp}$ apart. This could facilitate the occurrence of illegitimate recombination events within the LMW-GS genes and result in novel allelic variations, such as chimeric genes [9]. Both homologous and illegitimate recombination may occur at the Glu-3 and Glu-1 loci [9,39], resulting in the formation of novel allelic genes. In the current study, our results demonstrated that LMW-GS encoded by the Glu-3 locus in Brachypodium also display the properties of a complex gene family as those in Triticum and related species. The numbers of copies of LMW-GS genes in $B$. distachyon are probably less than that in T. aestivum according to the Southern blotting analysis but similar mechanisms for generating allelic variations at the Glu-3 locus might be present in Brachypodium. Frequent SNP and InDel variations, duplications and inversions of one and more repeats, by unequal crossing over, slippage or illegitimate recombination $[9,40]$, could result in the allelic variations observed at Glu-3 in B. distachyon.

\section{Phylogenetic evolutionary relationships of $B$. distachyon} with Triticum and related species as revealed by Glu-3 loci $B$. distachyon. has been shown to be much more closely related to wheat, barley and rice than to sorghum, rye or maize $[19,20]$. Recent studies have shown that $B$. distachyon is closely related to the tribe Triticeae and $A e$. tauschii, the donor of $\mathrm{D}$ genome of hexaploid wheat 
[18,41]. The analysis of bacterial artificial chromosome (BAC) end sequences (BES) of Brachypodium genome also revealed a closer relationship between Brachypodium and Triticeae than Brachypodium and rice or maize [42]. In the present work, phylogenetic tree based on the LMW-m type genes (Figure 5) indicated that Brachypodium is more closely related to Aegilops than to wheat, especially much closer to Ae. markgrafii (CC), Ae. umbellulata (UU), Ae. uniaristata (NN) and Ae. tauschii (DD). On the other hand, results revealed by the LMW-i type genes demonstrated that $B$. distachyon was closer to hexaploid common wheat and Ae. markgrafii than to Ae. uniaristata and Ae. comosa. It has been argued that the LMW-m type genes could be the progenitor of LMW-i and LMW-s type genes [32]. The HQ220202 and HQ220204 from $B$. distachyon and GQ870241 from the $\mathrm{U}$ genome of Ae. umbellulata were clustered into a clade while GQ870250 from the C genome of Ae. markgrafii had higher similarity with GQ870241. These 4 LMW-GS genes all had 9 cysteine residues located at a highly conserved position (Figure 4), indicating that B. distachyon is more closely related to Ae. markgrafii and Ae. umbellulata. Our results further supported the recent report that the $\mathrm{C}$ and $\mathrm{U}$ genomes appear to be closely related [32].

\section{Evolution of Glu-1 and Gli-1 loci in B. distachyon}

Our work demonstrated that $B$. distachyon grains had similar compositions of albumins, globulins, and LMWGS with these of wheat, but with fewer gliadins and HMW-GS. This suggests that, although the Glu-3 loci are highly conserved among Brachypodium, Aegilops, Triticum and other related cereal species, the Glu-1 and Gli-1 loci in B. distachyon could undergo dramatic divergence during its evolutionary process. A recent report has shown that a single copy of HMW glutenin gene with a premature stop codon was found in Brachypodium, and its structure was considered to be different from the wheat HMW glutenin gene [43]. However, we identified a HMW glutenin subunit with a lower expression level in Bd21 by a proteomic approach [25] and its encoding gene has been recently cloned in our lab (data not shown). This suggests that the Glu-1 is also conserved in Brachypodium.

In common wheat, LMW-GS are encoded by the genes at the orthologous Glu-A3, Glu-B3 and Glu-D3 loci on the short arms of group 1 chromosomes (1AS, $1 \mathrm{BS}$ and 1DS), which are closely linked with the Gli-A1, Gli-B1 and Gli-D1 loci encoding gliadins [44]. The physical relationships of Glu-3 and Gli-1 genes showed that gliadin or gliadin-like genes can distribute between two typical LMW-GS genes [45] and different types of LMW-GS can locate separately $[9,38]$. This can potentially result in formation of different chimeric genes between gliadin and the LMW-GS genes due to crossing over and illegitimate recombination between or in the Gli-1 and Glu-3 loci in wheat and related species $[9,46]$. Therefore, some modified LMW-GS may also be present in Brachypodium as reported in wheat [30].

According to our results, $B$. distachyon grains had very few gliadins when separated by the same extraction method as for wheat. Larré et al. also only found a few putative avenin-like proteins in B. distachyon [24]. We speculate that most of the gliadins in $B$. distachyon may have evolved into LMW-GS, most likely the LMW-C subunits. This may explain why Brachypodium contained abundant LMW-GS especially the LMW-C type subunits than wheat. Recent reports strongly support this scenario: some modified LMW-GS in wheat were identified by 2-DE and MALDI-TOF-MS, which might belong to modified $\alpha / \beta$ - and $\gamma$-gliadins [30]. It is also possible that most of the gliadin genes were pseudogenes and thus silent in mature grains due to premature stop codons as those in wheat, rice, maize and other cereals $[47,48]$.

Both globulin and glutenin genes are specifically expressed in seed developing tissues. Particularly, glutenin genes have a higher expression level than globulin genes $[43,49]$. Since fewer HMW-GS and no gliadins are expressed in the grains, the LMW glutenin subunits with higher expression level could be important grain storage protein in Brachypodium.

\section{Conclusion}

Brachypodium was more closely related to Ae. markgrafii and Ae. umbellulata than to T. aestivum; it possesses a highly conserved Glu-3 locus. The presence of LMW-GS in $B$. distachyon $\mathrm{t}$ warrants its usage as a model plant system for wheat quality research.

\section{Methods}

\section{Plant materials}

Six $B$. distachyon accessions were used in this work, including 5 hexaploid genotypes $(2 \mathrm{n}=6 \mathrm{x}=30)$ : $\mathrm{Bd} 4$ (PI208216), Bd10 (PI226452), Bd11 (PI226629), Bd13 (PI233228) and Bd16 (PI239715), and 1 diploid accession Bd21 $(2 n=10)$. All accession seeds were kindly provided by Dr. John Vogel, USDA-ARS, Albany, CA and Dr. Chengtao Lin, Institute of Crop Sciences, Chinese Academy of Agricultural Sciences (CAAS). Hexaploid common wheat varieties (Triticum aestivum L.) Chinese Spring (CS), and Kontrast were used as control in the study.

\section{Grain protein extraction, SDS-PAGE, RP-HPLC, Western blotting and Southern blotting}

B. distachyon seeds (50mg) were ground to powder and used to extract different grain proteins. The albumins, globulins and gliadins were extracted by distilled water, dilute salt solutions and $70 \%$ ethanol, respectively. The 
method of glutenin extraction and SDS-PAGE were adopted from Yan et al. [50]. The total albumins and globulins were extracted from $50 \mathrm{mg} \mathrm{B}$. distachyon grains according to Gao et al. [26]. Same volume $(15 \mu \mathrm{l})$ for each sample was loaded per lane of the gels. SDS-PAGE was performed with a Bio-Rad PROTEAN II XL based on the previously described method [50]. Reverse-phase high performance liquid chromatography (RP-HPLC) was performed on the basis of the method of Gao et al. [51]. A polyclonal antibody (CIPGLERPWQQQPL) specific for wheat LMW glutenin subunits was developed for Western blotting analysis and the detailed procedures were according to $\mathrm{Li}$ et al. [52]. The procedures of Southern blotting were according to Yue et al. [53] with minor modifications. Total genomic DNA was isolated from young leaves of $\mathrm{Bd} 21$ using a modified cetyltrimethyl- ammonium bromide protocol [54] and was quantified after RNase treatment. Considering that there were no BamHI, EcoRI, and HindIIII restriction sites in LMW-GS genes, the genomic DNA were digested with the three enzymes. The digested products were electrophoresed using $0.8 \%$ agarose gel and blotted onto a Hybond-N+ nylon membrane (Amersham, Buchinghamshire, UK) with alkaline transfer buffer $(0.4 \mathrm{M} \mathrm{NaOH})$. The PCR production of LMW-GS gene (FJ615311) from Chinese Spring were used as probes and the positive plasmid of LMW-GS gene was used as amplified template in above PCR system. Probe labeling, hybridization and detection of the LMW-GS genes were performed using the DIG High Prime DNA Labeling and Detection Starter Kit II (Roche, Mannheim, Germany), following the instructions of manufacturer. Four post-hybridization washes were performed as following: (1) Wash $2 \mathrm{x}$ $5 \mathrm{~min}$ in ample $2 \times \mathrm{SSC}, 0.1 \% \mathrm{SDS}$ at $25^{\circ} \mathrm{C}$ under constant agitation. (2) Wash $2 \times 15 \mathrm{~min}$ in $0.5 \times \mathrm{SSC}, 0.1 \%$ SDS (prewarmed to wash temperature) at $68^{\circ}$ Cunder constant agitation.

\section{DNA extraction and PCR amplification}

Genomic DNA was extracted from $30 \mathrm{mg}$ leaves of Brachypodium seedlings 7 days after germination with cetytrimethylammonium bomide (CTAB) method as reported by Murray and Thompson [54]. Two pair of primers (Primer $1+2$ and primer $7+8$ ) as described by Pei et al. [6] and Jiang et al. [55] for amplifying wheat LMW-GS genes were used to amplify the complete open reading fragments (ORFs) of the LMW glutenin genes of $B$. distachyon. PCR reaction in a $30 \mu$ l volume was performed using a $\mathrm{S} 1000^{\mathrm{m}}$ thermal cycler (Bio-Rad, USA) with the following program: an initial step of $94^{\circ} \mathrm{C}$ for $4 \mathrm{~min}, 34$ cycles of $94^{\circ} \mathrm{C}$ for $45 \mathrm{~s}, 58^{\circ} \mathrm{C}$ for $1 \mathrm{~min}$ and $72^{\circ} \mathrm{C}$ for $80 \mathrm{~s}$, and a final step of $10 \mathrm{~min}$ at $72^{\circ} \mathrm{C}$. The recombined DNA clones were sequenced by TaKaRa
Biotech Inc., Japan. Each clone was sequenced three times to avoid possible error.

\section{Sequence comparison and SNPs/InDels identification}

Bioedit 7.0 was used to conduct complete multiple alignment based on the complete nucleotide of cloned LMW-GS genes and other genes from GenBank. Single-nucleotide polymorphisms (SNPs) and insertions/ deletions (InDels) among LMW glutentin genes from B. distachyon as well as Aegilops and Triticum species were identified based on the multiple alignments [10].

\section{MALDI-TOF-MS}

The deduced proteins of cloned LMW-GS genes were further confirmed by matrix-assisted laser desorption/ ionization time-off mass spectrometry (MALDI-TOFMS). Based on the deduced amino acid sequences of LMW-GS genes cloned in this work, the theoretical mass spectra of trypsin digested LMW-GS were predicted by using the bioinformatic program PeptideMass (http:// www.expasy.ch/tools/pep-tide-mass. html). 5 protein bands $(4-1,21-1,21-2,13-1$ and $10-1)$ on SDS-PAGE gels (Figure 1e), corresponding to deduced molecular mass of cloned genes were selected for MS analysis. Protein bands were excised manually and their in-gel trypsin digestions were performed according to Gao et al. [26]. MALDI-TOF-MS identifications were conducted by searching against the NCBInr databases through the MASCOT (http://www.matrixscience.com) search engine and the putative Brachypodium protein database (http:// www.brachypodium.org) [13]. Finally, a comparative analysis between predicted and MS detected mass spectra was performed.

\section{Phylogenetic analysis}

MEGA4.1 was used to construct phylogenetic trees with complete nucleotide coding sequences of LMW-GS and the detailed steps were based on Wang et al. [32].

\section{Additional files}

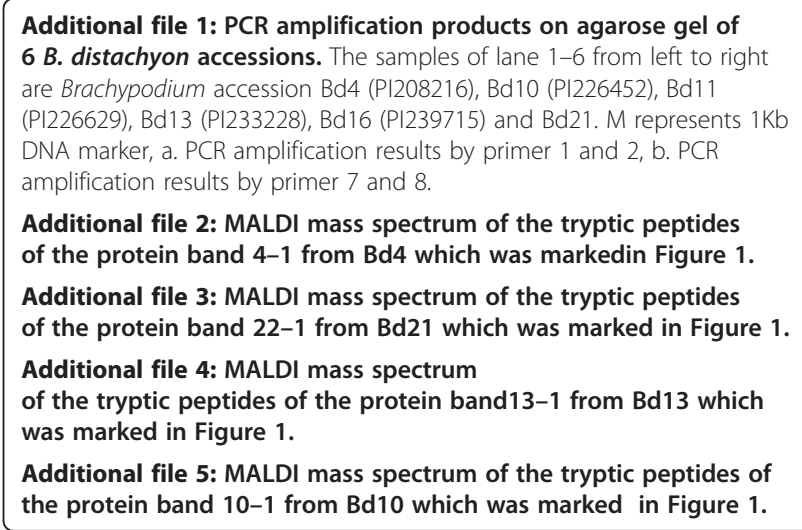


Additional file 6: MALDI mass spectrum of the tryptic peptides of the protein band 21-2 from Bd21 which was marked in Figure 1.

Additional file 7: Protein identification of 21-2 in $B$. distachyon by MALDI-TOF-MS.

\section{Authors' contributions}

SW participated in most of the experiments and data analysis, including experimental designs, protein extraction and separation, evolutionary analysis, etc. KW did Southern-blotting, GC took part in experiment of Western-blotting and $\mathrm{XH}$ participated in cloning the genes. ZY and $\mathrm{XL}$ did RP-HPLC. DL took part in some work of analyzing the result of LMW-GS mass spectrum. $Y Y, X Y$ and $W M$ took part in designing and supervising the study. SW, YY and WM participated in drafting the manuscript. SLK Hsam, R Appels gave valuable advice on manuscript preparation. All authors have read and approved the final manuscript.

\section{Acknowledgements}

This research was financially supported by grants from the National Natural Science Foundation of China (30830072, 31101145), the Chinese Ministry of Science and Technology (2009CB118303) and the National Key Project for Transgenic Crops of China (2011ZX08009-003-004, 2011ZX08002004).

\section{Author details}

'Key Laboratory of Genetics and Biotechnology, College of Life Science, Capital Normal University, 100048 Beijing, China. ${ }^{2}$ Institute of Crop Sciences, Chinese Academy of Agricultural Sciences/National Key Facility for Crop Gene Resources and Genetic Improvement, 100081 Beijing, China. ${ }^{3}$ Division of Plant Breeding and Applied Genetics, Technical University of Munich, D-85350 Freising-Weihenstephan, Germany. ${ }^{4}$ State Agriculture Biotechnology Centre, Murdoch University; Western Australian Department of Agriculture and Food, Perth, WA 6150, Australia.

Received: 8 May 2012 Accepted: 30 October 2012

Published: 21 November 2012

\section{References}

1. Shewry PR, Halford NG: Cereal seed storage proteins: structures, properties and role in grain utilization. J Exp Bot 2002, 53:947-958.

2. Payne PI: Genetics of wheat storage proteins and the effect of allelic variation on bread-making quality. Ann Rev Plant Physiol 1987, 38:141-153.

3. $\mathrm{Xu} \mathrm{H}$, Zhang $X Q$, Wang XP, Guo AG: Molecular cloning of Agropyron intermedium low-molecular-weight glutenin subunit genes from a Triticum aestivum-Ag. Intermedium addition line-TAl-13. Acta Bot Sin 2004, 46:595-602.

4. Yan Y, Zheng J, Xiao Y, Yu J, Hu Y, Cai M, Li Y, Hsam SLK, Zeller FJ: Identification and molecular characterization of a novel y-type Glu-D $D^{t} 1$ glutenin gene of Aegilops tauschii. Theor Appl Genet 2004, 108:1349-1358.

5. Luo Z, Chen FG, Feng DS, Xia GM: LMW-GS genes in Agropyron elongatum and their potential value in wheat breeding. Theor Appl Genet 2005, 111:272-280.

6. Pei YH, Wang AL, An XL, Li XH, Zhang YZ, Huang XQ, Yan YM: Characterization and comparative analysis of three low molecular weight glutenin C-subunit genes isolated from Aegilops tauschii. Can J Plant Sci 2007, 87:273-280

7. Guo ZF, Dong P, Long XY, Wei YM, Zhang LJ, Zheng YL: Molecular characterization of LMW prolamines from Crithopsis delileana and the comparative analysis with those from Triticeae. Hereditas 2008, 145:204-211.

8. Li XH, Wang AL, Xiao YH, Yan YM, He ZH, Appels R, Ma W, Hsam SLK, Zeller $\mathrm{FJ}$ : Cloning and characterization of a novel low molecular weight glutenin subunit gene at the Glu-A3 locus from wild emmer wheat (Triticum turgidum L. var. dicoccoides). Euphytica 2008a, 159:181-190.

9. Li XH, Ma WJ, Gao LY, Zhang YZ, Wang AL, Ji KM, Wang K, Appels R, Yan YM: A novel chimeric LMW-GS gene from the wild relatives of wheat Ae. kotschyi and Ae. juvenalis: evolution at the Glu-3 loci. Genetics 2008b, 180:93-101.

10. Li XH, Wang K, Wang SL, Gao LY, Xie XX, Hsam SLK, Zeller FJ, Yan YM: Molecular characterization and comparative transcriptional analysis of LMW-m-type genes from wheat (Triticum aestivum L.) and Aegilops species. Theor Appl Genet 2010, 121:845-856.
11. Borght AVD, Vandeputte GE, Derycke V, Brijs K, Daenen G, Delcour JA: Extractability and chromatographic separation of rice endosperm proteins. J Cereal Sci 2006, 44:68-74.

12. $X u Y, M c C o u c h ~ S R$, Zhang Q: How can we use genomics to improve cereals with rice as a reference genome? Plant Mol Biol 2005, 59:7-26.

13. International Brachypodium Initiative: Genome sequencing and analysis of the model grass Brachypodium distachyon. Nature 2010, 463:763-768.

14. Ozdemir BS, Hernandez P, Filiz E, Budak H: Brachypodium Genomics. Int J Plant Genomics 2008, 2008:536104.

15. Draper J, Mur L, Jenkins G, Ghosh-Biswas G, Bablak P, Hasterok R, Routledge A: Brachypodium distachyon. A new model system for functional genomics in grasses. Plant Physiol 2001, 127:1539-1555.

16. Christiansen P, Didion T, Andersen C, Folling M, Nielsen K: A rapid and efficient transformation protocol for the grass Brachypodium distachyon. Plant Cell Rep 2005, 23:751-758.

17. Vogel J, Garvin D, Leong O, Hayden D: Agrobacterium mediated transformation and inbred line development in the model grass Brachypodium distachyon. Plant Cell Tiss Organ Cult 2006, 85:199-211.

18. Kumar S, Mohan A, Balyan HS, Gupta PK: Orthology between genomes of Brachypodium, wheat and rice. BMC Research Notes 2009, 2:93.

19. Kellogg EA: Evolutionary history of the grasses. Plant Physiol 2001, 125:1198-1205.

20. Vogel J, Gu Y, Twigg P, Lazo G, Laudencia-Chingcuanco D, Hayden D, Donze T, Vivian L, Stamova B, Coleman-Derr D: EST sequencing and phylogenetic analysis of the model grass Brachypodium distachyon. Theor Appl Genet 2006, 113:186-195.

21. Bablak P, Draper J, Davey M, Lynch P: Plant regeneration and micropropagation of Brachypodium distachyon. Plant Cell Tiss Organ Cult 1995, 42:97-107.

22. Vogel J, Hill T: High-efficiency Agrobacterium-mediated transformation of Brachypodium distachyon inbred line Bd21-3. Plant Cell Rep 2008, 27:471-478

23. Laudencia-Chingcuanco DL, Vensel WH: Globulins are the main seed storage proteins in Brachypodium distachyon. Theor App/ Genet 2008, 117:555-563.

24. Larré C, Penninck S, Bouchet B, Lollier V, Tranquet O, Denery-Papini S, Guillon F, Rogniaux H: Brachypodium distachyon grain: identification and subcellular localization of storage proteins. J Exp Bot 2010, 61:1771-1783.

25. Wang K, Han XF, Dong K, Gao LY, Li HY, Ma WJ, Yan YM, Ye XG: Characterization of seed proteome in Brachypodium distachyon. J Cereal Sci 2010, 52:177-186.

26. Gao L, Wang AL, XH L, Dong K, Wang K, Appels R, Ma WJ, Yan YM: Wheat quality related differential expressions of albumins and globulins revealed by two dimensional difference gel electrophoresis (2-D DIGE). J Proteomics 2009, 73:279-296.

27. An X, Zhang Q, Yan Y, Li Q, Zhang Y, Wang A, Pei Y, Tian J, Wang H, Hsam SLK, Zeller FJ: Cloning and molecular characterization of three novel LMW-i glutenin subunit genes from cultivated einkorn (Triticum monococcum L.). Theor App/ Genet 2006, 113:383-395.

28. Sun X, Hu SL, Liu X, Qian WQ, Hao ST, Zhang AM, Wang DW: Characterization of the HMW glutenin subunits from Aegilops searsii and identification of a novel variant HMW glutenin subunit. Theor App/ Genet 2006, 113:631-641.

29. Dong L, Zhang XF, Liu DC, Fan HJ, Sun JZ, Zhang ZJ, Qin HJ, Li B, Hao ST, Li ZS, Wang DW, Zhang AM, Ling HQ: New insights into the organization, recombination, expression and functional mechanism of low molecular weight glutenin subunit genes in bread wheat. PLoS One 2010, 5:10.

30. Muccilli V, Cunsolo V, Saletti R, Foti S, Margiotta B, Scossa F, Masci S, Lafiandra D: Characterisation of a specific class of typical low molecular weight glutenin subunits of durum wheat by a proteomic approach. J Cereal Sci 2010, 51:34-139.

31. Masci S, Rovelli L, Kasarda DD, Vensel WH, Lafiandra D: Characterisation and chromosomal localisation of C-type low molecular weight glutenin subunits in the bread wheat cultivar Chinese Spring. Theor Appl Genet 2002, 104:422-428

32. Wang SL, Li XH, Wang K, Wang XZ, Li SS, Zhang YZ, Guo GF, Zeller FJ, Hsam SLK, Yan YM: Phylogenetic analysis of $C, M, N$ and $U$ genomes and their relationships with Triticum and other related genomes as revealed by LMW-GS genes at Glu-3 loci. Genome 2011, 54:273-284.

33. D'Ovidio R, Masci S: The low-molecular-weight glutenin subunits of wheat gluten. J Cereal Sci 2004, 39:321-339. 
34. Harberd NP, Bartels D, Thompson RD: Analysis of the gliadin moltigene loci in bread wheat using nullisomic-tetrasomic lines. Mol Gen Genet 1985, 198:234-242.

35. Huang XQ, Cloutier S: Molecular characterization and genomic organization of low molecular weight glutenin subunit genes at the Glu-3 loci in hexaploid wheat (Triticum aestivum L.). Theor App/ Genet 2008, 116:953-966

36. Sabelili PA, Shewry PR: Characterization and organization of gene families at the Gli-1 loci of bread and durum wheats by restriction fragment analysis. Theor Appl Genet 1991, 83:209-216.

37. Cassidy BG, Dvorak J, Anderson OD: The wheat low-molecular-weight glutenin genes: characterization of six new genes and progress in understanding gene family structure. Theor Appl Genet 1998, 96:743-750.

38. Wicker T, Yahiaoui N, Guyot R, Schalgenhauf E, Liu ZD, Dubcovsky J, Keller B: Rapid genome divergence at orthologous low molecular weight glutenin loci of the $A$ and $A^{m}$ genomes of wheat. Plant Cell 2003, 15:1186-1197.

39. Zhang YZ, Li XH, Wang AL, An XL, Zhang Q, Pei YH, Gao LY, Ma WJ, Appels $R$, Yan YM: Novel x-type HMW glutenin genes from Aegilops tauschii and their implications on the wheat origin and evolution mechanism of Glu-D1-1 proteins. Genetics 2008, 178:23-33.

40. Anderson OD, Greene FC: The characterization and comparative analysis of high-molecular-weight glutenin genes from genomes $A$ and $B$ of a hexaploid bread wheat. Theor Appl Genet 1989, 77:689-700.

41. Bortiri E, Coleman-Derr D, Lazo GR, Anderson OD, Gu YQ: The complete chloroplast genome sequence of Brachypodium distachyon: sequence comparison and phylogenetic analysis of eight grass plastomes. BMC Research Notes 2008, 1:61.

42. Huo N, Lazo GR, Vogel JP, You FM, Ma YQ, Hayden DM, Coleman-Derr D, Hill TA, Dvorak J, Anderson OD, Luo MC, Gu YQ: The nuclear genome of Brachypodium distachyon: analysis of BAC end sequences. Funct Integr Genomics 2008, 8:135-147.

43. Gu YQ, Wanjugi H, Coleman-Derr D, Kong XY, Anderson OD: Conserved globulin gene across eight grass genomes identify fundamental units of the loci encoding seed storage proteins. Funct Integr Genomics 2010, 10:111-122.

44. Singh NK, Shepherd KW: Linkage mapping of genes controlling endosperm storage proteins in wheat. 1. Genes on the short arms of group 1 chromosomes. Theor Appl Genet 1988, 75:628-641.

45. Gao S, Gu YQ, Wu J, Coleman-Derr D, Huo N, Crossman C, Jia J, Zuo Q, Ren Z, Anderson OD, Kong X: Rapid evolution and complex structural organization in genomic regions harboring multiple prolamin genes in the polyploid wheat genome. Plant Mol Biol 2007, 65:189-203.

46. Nagy IJ, Takàcs I, Juhász A, Tamás L, Bedo Z: Identification of a new class of recombinant prolamin genes in wheat. Genome 2005, 48:840-847.

47. Xie ZZ, Wang CY, Wang K, Wang SL, Li XH, Zhang Z, Ma WJ, Yan YM: Molecular characterization of the celiac disease epitope domains in a-gliadin genes in Aegilops tauschii and hexaploid wheats (Triticum aestivum L.). Theor App/ Genet 2010, 121:1239-1251.

48. $\mathrm{Xu} \mathrm{JH}$, Messing J: Amplification of prolamin storage protein genes in different subfamilies of the Poaceae. Theor Appl Genet 2009, 119:1397-412

49. Anderson OD: EST mining for gene structure and expression analysis of genes in the region of the wheat high-molecular-weight glutenin loci. Genome 2009, 52:726-740.

50. Yan Y, Hsam SLK, Yu JZ, Jiang Y, Zeller FJ: Allelic variation of the HMW glutenin subunits in Aegilops tauschii accessions detected by sodium dodecyl sulphate (SDS-PAGE), acid polyacrylamide gel (A-PAGE) and capillary electrophoresis. Euphytica 2003, 130:377-385

51. Gao LY, Ma WJ, Chen J, Wang K, Jing L, Wang SL, Bekes F, Appels R, Yueming $Y$ : Characterization and Comparative Analysis of Wheat High Molecular Weight Glutenin Subunits by SDS-PAGE, RP-HPLC, HPCE, and MALDI-TOF-MS. J Agr Food Chem 2010, 58:2777-2786.

52. Li QY, Ji KM, Zhang YZ, An XL, He ZH, Xia XC, Yan YM: Characterization of monoclonal antibodies specific to wheat glutenin subunits and their correlation with quality parameters. Can J Plant Sci 2009, 89:11-19.

53. Yue SJ, Li H, Li YW, Zhu YF, Guo JK, Liu YJ, Chen Y, Jia X: Generation of transgenic wheat lines with altered expression levels of 1Dx5 high-molecular weight glutenin subunit by RNA interference. J Cereal Sci 2008, 47:1-161
54. Murray M, Thompson WF: Rapid isolation of high molecular weight plant DNA. Nucleic Acids Res 1980, 8:4321-4325.

55. Jiang CX, Pei YH, Zhang YZ, Li XH, Yao DN, Yan YM, Hsam SLK, Zeller FJ: Molecular cloning and characterization of four novel LMW glutenin subunit genes from Aegilops longissima, Triticum dicoccoides and T. zhukovskyi. Hereditas 2008, 145:92-98.

doi:10.1186/1471-2229-12-221

Cite this article as: Wang et al:: Molecular characterization of LMW-GS genes in Brachypodium distachyon L. reveals highly conserved Glu-3 loci in Triticum and related species. BMC Plant Biology 2012 12:221.

\section{Submit your next manuscript to BioMed Central and take full advantage of:}

- Convenient online submission

- Thorough peer review

- No space constraints or color figure charges

- Immediate publication on acceptance

- Inclusion in PubMed, CAS, Scopus and Google Scholar

- Research which is freely available for redistribution 